\title{
Spectrophotometric analysis of feldspathic porcelain with silver ion
}

\author{
Jihyun Kim', Kyeongwoo Song ${ }^{2}$, Sera Noh³, Kyelim Yun³, Kwidug Yun* \\ 'Department of Prosthodontics, School of Dentistry, Chonnam National University, Gwangju, Republic of Korea \\ ${ }^{2}$ Alphadent, Goyang, Republic of Korea \\ ${ }^{3} \mathrm{NCL}$ Korea, Gwangju, Republic of Korea
}

Purpose: This study was evaluated the shade of feldspathic porcelain with various concentration of silver ion. Materials and Methods: The control group was conventional feldspathic porcelain with no silver ion, the experimental groups were the feldpathic porcelain with $5 \%, 10 \%, 20 \%, 30 \%$ silver ion. The number of specimens on the each group was 5 . Commission Internationale de I'Eclairage (CIE) L*a*b* parameters were recorded twice for each specimen with a spectrophotometer (Model CM-2600d, Minolta, Japan). One-way Anova was used for statistical analysis. Results: $L$ value was similar. a value was increasing and $b$ value was decreasing with silver ion statistically significantly. $\Delta \mathrm{E}$ was increasing according to silver ion significantly. Conclusion: The shade of feldspahtic porcelain was influenced by silver ion. Ag ion under 10\% concentration is acceptable clinically. (J Dent Rehabil Appl Sci 2015;31(1):20-5)

Key words: feldspathic porcelain; silver ion; shade; esthetic properties

\section{서론}

최근 심미에 대한 관심이 높아짐에 따라 도재를 이용 한 고정성 보철 수복물 치료가 보철치료에서 큰 비중을 차지 하고 있다. 이러한 고정성 보철물은 환자의 구강 위 생 능력과 식습관 그리고 유지 관리에 따라 수명에 많은 차이가 나게 된다. 윤의 논문에 따르면 고정성 보철물의 합병증은 생물학적 합병증과 기계적 합병증으로 나뉘게 되는데, 고정성 보철물의 생물학적 합병증은 치주 질환 (37.5\%), 치아 우식증(19.0\%), 그리고 치수 질환(10.8\%) 순이었고, 기계적 문제점은 변연 결함(18.4\%), 보철물 파 절 $(4.2 \%)$, 유지력 상실 $(3.9 \%)$, 치아 파절 $(3.6 \%)$, 그리고 식편압입 $(2.6 \%)$ 순이었다. ${ }^{1}$ 즉 절반 이상의 빈도로 고정 성 보철물의 수명을 단축시키는 합병증을 일으키는 것 으로 치주질환, 치아 우식증, 치수 질환등의 구강내 미생

*Correspondence to: Kwidug Yun

Associate Professor,_Department of Prosthodontics, School of Dentistry, Chonnam National University, 33, Yongbong-ro, Buk-gu, Gwangju, 500-757, Republic of Korea Tel: +82-62-530-5631, Fax: +82-62-530-5639, E-mail: ykd@jnu.ac.kr

Received: February 6, 2015/Last Revision: March 6, 2015/Accepted: March 2, 2015
물에 대한 생물학적인 문제와 연관이 있었다. 더욱이 고 정성 보철물은 구강내에 합착시 환자가 보철물을 제거할 수 없으므로 구강위생관리를 완벽하게 하기 어려운 상황 이다. 그러므로 재료 자체가 지속적으로 구강내에서 항 균성을 나타낼 수 있다면 이러한 합병증을 줄일 수 있을 것이다.

은은 대표적인 금속계 항균 물질로서, 인체에 무해하 며 미생물의 신진대사 기능을 억제하여 약 650여종의 유 해 세균에 항균 효과가 있는 것으로 알려져 있는 물질이 다. ${ }^{2}$ 또한 은은 다른 항생제에 비하여 내성을 갖는 미생 물의 수가 적기 때문에 은을 이용한 다양한 활용 방법이 연구되고 있다. ${ }^{3}$ 은의 항균성에 대한 활용의 많은 부분은 페인트, 실리콘, 항균 섬유등 다양한 일상 생활 분야에 이 용되지만 생체재료쪽의 응용은 아직 제한적이었다. 그러 나, 최근에는 은나노 입자를 고분자에 포함된 상태로 제 
조하는 방법 이외에 겉 표면에 은을 코팅함으로서 활용 하는 방법이 알려지면서 의료기기에 적용시키는 많은 연구들이 이루어지고 있다..$^{46}$ 은의 항균성을 치과용 보 철 분야에 적용하기 위해서는 2 가지의 방법이 있는데 도재 소부용 금속에 유리될 수 있는 은이온을 첨가시키 거나 도재에 은을 첨가시키는 방법이다. 그러나 도재소 부용 금속에 은을 첨가시 융점을 낮추거나 열팽창계수 를 높이고, 도재의 황변을 일으킨다고 알려져 있기 때문 에 은 첨가량의 조절은 매우 중요하다. ${ }^{7}$ 그러므로 이번 실험에서는 장석계 도재에 다양한 농도의 은 이온을 첨 가하였을때 도재의 색조에 어떠한 영향을 미치는지 알 아보고자 한다.

\section{연구 재료 및 방법}

\section{1. 실험 시편의 제작}

은이 포함되지 않은 통상적인 장석계 도재(Noritake EX-3, Kuraray Noritake Dental Inc., Miyoshi, Japan)를 대조군으로 사용하고, 은 이온을 $5 \%, 10 \%, 20 \%, 30 \%$ 로 혼합하여 실험군으로 이용하였다(Table 1, Fig. 1). Dentin porcelain을 이용하여 두께 $2 \mathrm{~mm}$, 직경 $15 \mathrm{~mm}$ 의 디스크 형태로 제조회사의 온도에서 2 번에 나누어 소성하여 제작하였다. 각 그룹당 5 개의 시편을 제작하 였다.

Table 1. Control and experimental groups

\begin{tabular}{cl}
\hline Groups & \multicolumn{1}{c}{ Composition } \\
\hline $0 \% \mathrm{Ag}$ & Feldspathic porcelain + no Ag \\
(control group) & \\
$5 \% \mathrm{Ag}$ & Feldspathic porcelain $+5 \% \mathrm{Ag}$ \\
$10 \% \mathrm{Ag}$ & Feldspathic porcelain $+10 \% \mathrm{Ag}$ \\
$20 \% \mathrm{Ag}$ & Feldspathic porcelain $+20 \% \mathrm{Ag}$ \\
$30 \% \mathrm{Ag}$ & Feldspathic porcelain $+30 \% \mathrm{Ag}$ \\
\hline
\end{tabular}

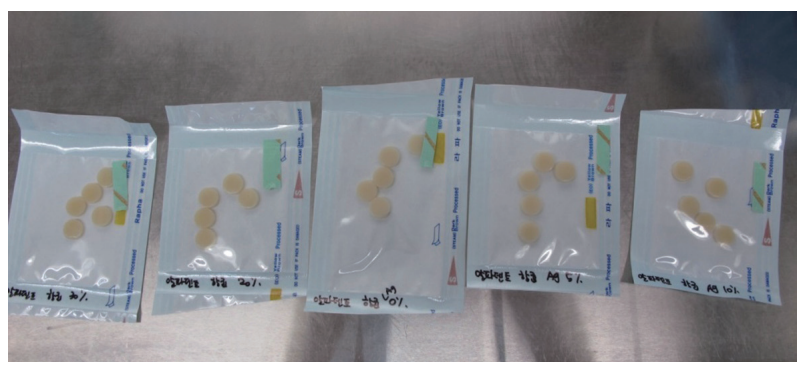

Fig. 1. Digital photographs of speimens.

\section{2. 분광 측색학적 분석}

측정시 일정한 위치로 위치시키기 위해 고정판을 이 용하였으며, 고정판의 내부는 외부 광원을 차단하기 위 해 검은색을 이용하였다. 각 시편의 색조는 분광 측색기 (CM-2600d, Minolta Co. Ltd, Osaka, Japan)을 이용하 여 각 시편당 2 번씩 측정되었다. 분광 측색기는 제조사 의 지시대로 기기의 색조정을 시행하여 이용하였다. 측 정된 값은 시스템의 전용 컴퓨터 프로그램을 이용하여 $\mathrm{CIE} \mathrm{L}^{*} \mathrm{a}^{*} \mathrm{~b}$ 의 값을 얻었다. 대조군과 실험군의 $\mathrm{L}^{*}, \mathrm{a}^{*}$, $\mathrm{b}^{*}$ 값을 이용하여 다음과 같이 색차 $(\Delta \mathrm{E})$ 을 계산하였다. 그룹당 얻어진 $\mathrm{L}^{*}, \mathrm{a}^{*}, \mathrm{~b}^{*}$ 값 및 $\Delta \mathrm{E}$ 값은 통계처리를 시 행하여 평균값을 이용하였다(Fig. 2).

$$
\begin{aligned}
& \Delta \mathrm{E}=\left(\Delta \mathrm{L}^{* 2}+\Delta \mathrm{a}^{* 2}+\Delta \mathrm{b}^{* 2}\right)^{1 / 2} \\
& \begin{aligned}
\Delta \mathrm{L}^{*} & =\mathrm{L}^{*} \text { control - } \mathrm{L}^{*} \text { experiment, } \Delta \mathrm{a}^{*} \\
& =\mathrm{a}^{*} \text { control - } \mathrm{a}^{*} \text { experiment, } \Delta \mathrm{b}^{*} \\
& =\mathrm{b}^{*} \text { control - } \mathrm{b}^{*} \text { experiment }
\end{aligned}
\end{aligned}
$$

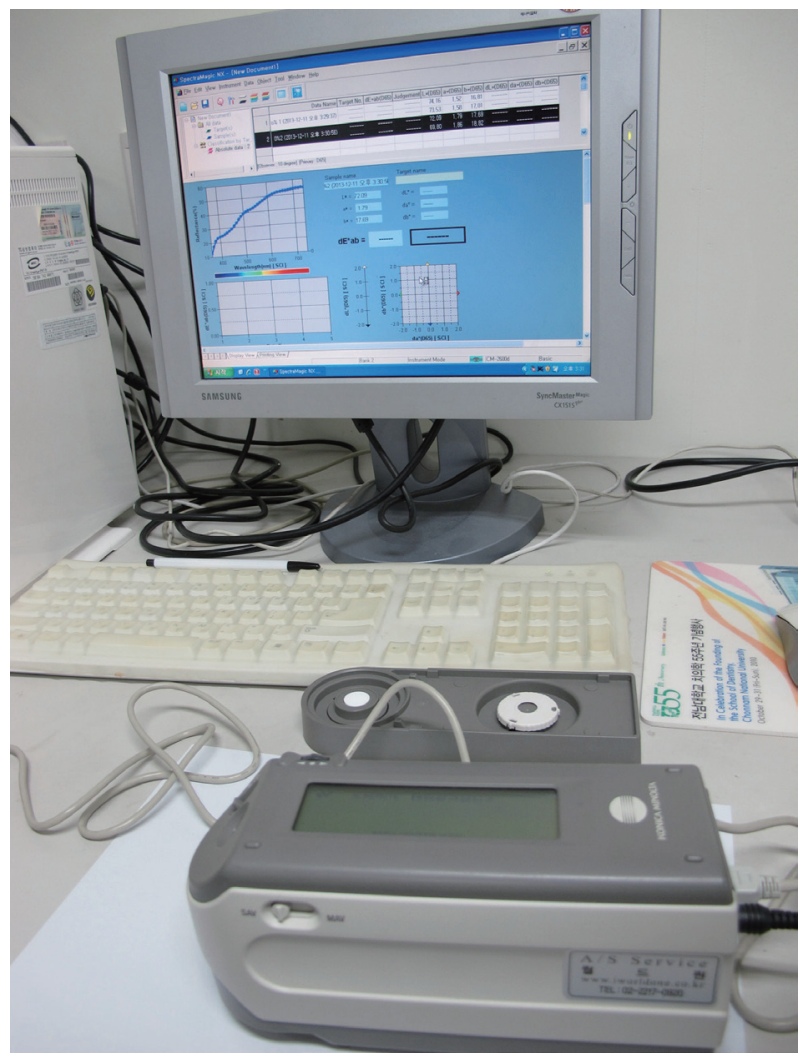

Fig. 2. Spectrophotometric analysis. The machine for spectrophotometric analysis (CM-2600d) and CIE $L^{*} a * b *$ software are shown. 


\section{3. 통계 분석}

얻어진 $\mathrm{L}^{*}, \mathrm{a}^{*}, \mathrm{~b}^{*}$ 값 및 $\Delta \mathrm{E}$ 값은 SPSS Ver. 17.0 (SPSS Inc, Chicago, IL, USA) 프로그램을 이용해 실험 결과를 Levene의 등분산 검정을 시행한 후, One-way ANOVA 검정을 이용하여 통계 처리 하였다. 모든 검증은 유의 수준 0.05 수준에서 이루어졌다.

\section{결과}

$\mathrm{L}^{*}, \mathrm{a}^{*}, \mathrm{~b}^{*}$ 의 데이터를 통계 분석을 시행하기 위해 Levene의 등분산 검정을 시행한 결과 모두 등분산성을 만족하였다. $\mathrm{L}^{*}$ 값은 전반적으로 72 에서 73 의 값을 보 였으며 이는 통계적으로 유의한 차이가 없었다. 이는 은 이온의 첨가가 명도에는 영향을 미치지 않음을 의미한 다. a* 값은 은 이온의 함량이 높아질수록 통계적으로 유 의하게 감소하는 경향을 보였다. 은 이온의 함량에 관계 없이 모든 실험군에서 양의 값을 보여 빨간색의 값을 나
타냄을 알 수 있었으며, 은 함량이 높아질수록 빨간색의 채도값이 유의하게 낮아졌다. $\mathrm{b}^{*}$ 값은 은이온의 함량이 높아질수록 통계적으로 유의하게 증가하는 경향을 보였 다. 이 역시 은 이온의 함량에 관계없이 모든 실험군에 서 양의 값을 보여 노란색의 값을 나타냄을 알 수 있었 으며, 은 함량이 높아질수록 노란색의 채도가 진해짐을 알 수 있었다(Table 2, Fig. 3).

$\Delta \mathrm{E}$ 값은 두 가지 색의 차이를 나타내는 것으로서 실 험군에 비교해서 대조군의 색차가 얼마나 나는지 확인 하는 지표이다. $\Delta \mathrm{E}$ 값의 데이터도 통계 분석을 시행하 기 위해 levene 의 등분산검정을 시행한 결과 등분산성 을 만족하여 일원분산분석을 시행하였다. $\Delta \mathrm{E}$ 값은 은이 온의 함량이 증가할수록 통계적으로 유의하게 증가하 는 경향이 있다(Table 3, Fig. 4). 구강내에서 임상적으로 허용가능한 $\Delta \mathrm{E}$ 값이 3.7 임을 고려할때, ${ }^{8-10} 5 \%$ 와 $10 \%$ 의 은 이온이 첨가된 경우는 임상적으로 받아들여지지만, $20 \%$ 와 $30 \%$ 의 은 이온이 첨가된 경우는 쉽게 색차를 인 지가능함을 나타낸다.

Table 2. The mean and standard deviation $L^{*}, a^{*}, b^{*}$ parameters of each group

\begin{tabular}{cccc}
\hline Groups & L* $^{*}$ & $\mathrm{a}^{*}$ & $\mathrm{~b}^{*}$ \\
\hline $0 \% \mathrm{Ag}$ & $73.6080 \pm 1.7368$ & $1.5500 \pm 0.1554$ & $17.2600 \pm 0.7058$ \\
$5 \% \mathrm{Ag}$ & $73.1900 \pm 1.0838$ & $1.1840 \pm 0.4346$ & $19.3540 \pm 1.0826$ \\
$10 \% \mathrm{Ag}$ & $72.8700 \pm 1.8495$ & $0.6220 \pm 0.1899$ & $20.8120 \pm 1.3715$ \\
$20 \% \mathrm{Ag}$ & $72.1180 \pm 0.9154$ & $0.4680 \pm 0.1333$ & $22.5480 \pm 1.1106$ \\
$30 \% \mathrm{Ag}$ & $72.4220 \pm 1.6821$ & $0.3060 \pm 0.2609$ & $24.1240 \pm 0.7038$ \\
\hline
\end{tabular}
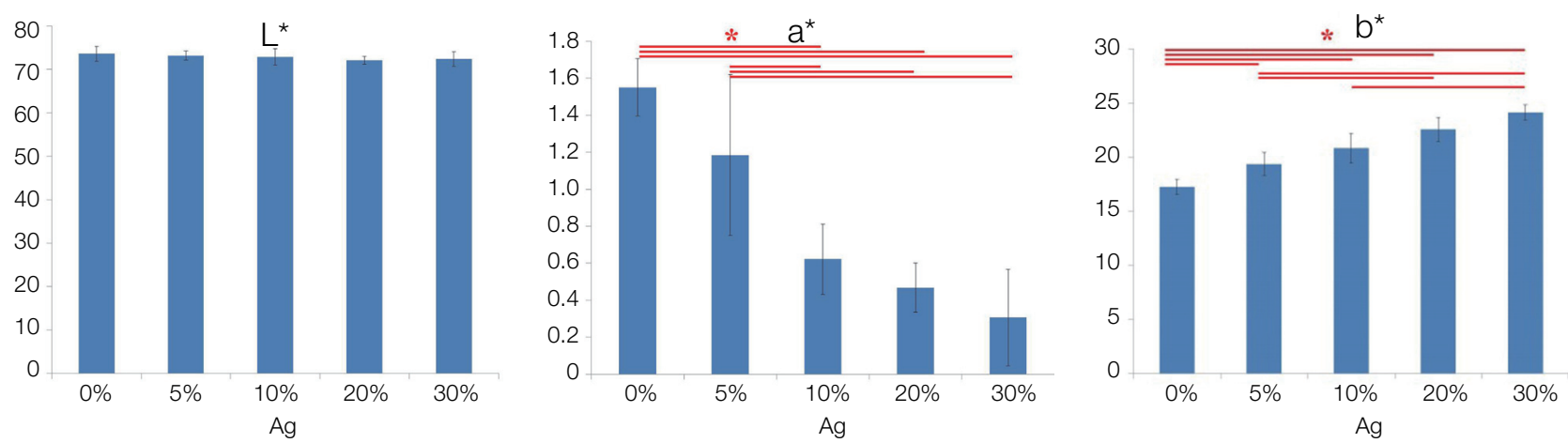

Fig. 3. Mean and standard deviation value of $L^{*}, a^{*}, b^{*}$ results. The $L^{*}$ coordinate is a measure of the lightnessdarkness of the specimen. The greater the $L^{*}$ is, the lighter the specimen. The $a^{*}$ coordinate is a measure of the chroma along the redgreen axis. A positive $a^{*}$ relates to the amount of redness, and a negative a* relates to greenness of a specimen. The $b^{*}$ coordinate is a measure of the chroma along the yellow-blue axis; that is, a positive $b^{*}$ relates to the amount of yellowness, while a negative $b^{*}$ relates to the blueness of the specimen.

* represents statistically significance between groups. 
Table 3. $\Delta \mathrm{E}$ vales between groups

\begin{tabular}{cc}
\hline Groups & $\Delta \mathrm{E}$ \\
\hline $0 \% \mathrm{Ag}-5 \% \mathrm{Ag}$ & $2.2165 \pm 0.5772$ \\
$0 \% \mathrm{Ag}-10 \% \mathrm{Ag}$ & $3.7261 \pm 1.0378$ \\
$0 \% \mathrm{Ag}-20 \% \mathrm{Ag}$ & $5.0412 \pm 1.0511$ \\
$0 \% \mathrm{Ag}-30 \% \mathrm{Ag}$ & $6.6990 \pm 0.6312$ \\
\hline
\end{tabular}

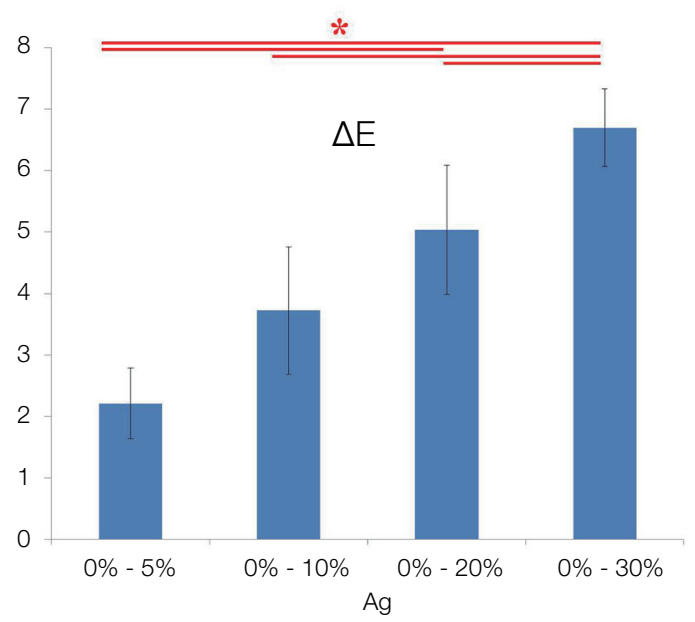

Fig. 4. Graph of $\Delta E$ results.

\section{고찰}

은은 오래전부터 사용되어온 대표적인 금속계 항균 물질이다. 은은 효소의 단백질을 구성하고 있는 아미노 산의 하나인 시스테인(cysteine)의 -SH기와 은 이온이 반응함으로서 S-Ag가 형성되어 미생물을 불활성화 시 키는 메커니즘으로 항균 효과를 나타낸다고 알려져 있 다. ${ }^{11}$ 혹은 미생물의 물질 대사 과정 중 활성 산소의 생 성을 유도할 수 있으며, 은 이온이 미생물의 세포질 막 에 있는 칼륨 이온을 방출시킴으로서 미생물을 불활성 시킨다는 보고가 있다. ${ }^{12}$ 어떠한 메커니즘을 통하든 은 이온이 강력한 항균 작용을 나타내며, 다양한 박테리아, 박테리아 스포어, 곰팡이, 바이러스 등을 효과적으로 불 활성화 시킬 수 있다. ${ }^{13}$ 이러한 항균 효과를 고정성 보철 물 치료 영역에 적용시키고자 하였다. 장석계 도재 수 복물에서 은을 첨가시킬때에는 2 가지의 방법이 있는데,
금속에 첨가시키거나 장석계 도재에 첨가시킬 수 있다. 금속에 은이온을 첨가시키면 합금의 유동성이 저하될 뿐만 아니라 금속의 융점이 낮아지고 열팽창 계수를 높 이기 때문에 도재 금속 수복물에서 금속의 성분을 변화 시키기에는 어려움이 있다. 그러므로 장석계 도재에 은 이온을 첨가하였는데, 일반적으로 은은 도재의 황변현 상을 일으킨다고 잘 알려져 있다. ${ }^{7}$ 그러므로 이번 실험 에서는 은 이온의 첨가가 장석계 도재의 색조에 영향을 미치는지 알아보고자 하였다.

색조 선택에 영향을 미치는 요소로는 입사광, 물체의 물리적 성질, 주변 환경, 관찰자의 주관적 판단 등에 의 해 영향을 받을 수 있으므로 관찰자와 광원 등조건에 따 라 다르게 보인다고 하였다. ${ }^{14}$ 일반적으로 색조의 평가 시에 가장 많이 이용되는 방법은 색 견본과 시편을 대 조해보는 것이다. 이는 사용이 편리하기 때문에 임상에 서 가장 많이 사용되고 있으나 주관적 요소, 주변 광원 등에 의해 선택의 일관성이 떨어지는 등의 단점으로 인 해 객관적이며 신뢰도 있는 색을 평가하기 위한 기계가 개발되고 있다. 그러므로 색을 $\mathrm{L}^{*}, \mathrm{a}^{*}, \mathrm{~b}^{*}$ 값으로 정량 화 할 수 있는 분광측색장치(spectrophotometer)를 이 용하는 것이 더 객관적인 데이터를 얻을 수 있다. 많이 이용되는 CIE system은 국제 조명 위원회(Commission Internationale de J' Eclairage)에 의해 채택된 것으로, 측 정의 결과를 $\mathrm{L}^{*}, \mathrm{a}^{*}, \mathrm{~b}^{*}$ 로 표현하는데, 이를 이용하여 색 을 정량화 할 수 있고 그에 따라 두 물체간의 색 차이 $(\Delta$ $\mathrm{E}$ 도 정량적으로 평가할 수 있다. ${ }^{15}$ 두 물체간에 색상의 차이인 $\Delta \mathrm{E}$ 값은 클수록 색조 차이가 많이 나고, 작을수 록 색조 차이를 인지하기 힘든 것으로, 1 보다 작은 경우 최상의 색조 조화를 이루며 1 - 2사이는 임상적으로 받 아들일 만 하며 2 이상은 부조화를 나타낸다고 알려져 있다. ${ }^{8}$ 그러나 인간의 눈은 $1 \Delta \mathrm{E}$ 값까지 색조 차이를 구 분할 수 있으나 광원 등 외부 요소를 표준화 할 수 없는 구강 내에서는 비교치아와 $3.7 \Delta \mathrm{E}$ 값의 차이가 보고 되 었다. ${ }^{9,10}$ Johnston 등도 ${ }^{16}$ 역시 3.7 이하이면 임상에서 받 아들여질만 하다고 하였다. ${ }^{13-15}$ 이 연구를 통해서 은 이 온의 첨가는 $\mathrm{L}^{*}$ 값에는 영향이 없었으나, $\mathrm{a}^{*}, \mathrm{~b}^{*}$ 값에는 영향을 미침을 알 수 있었다. 즉 은이온은 명도를 변화 시키지 않지만, 채도를 변화시킴으로서 색의 차이를 보 이게 한다. 이를 통해 $5 \%$ 와 $10 \%$ 의 은 이온의 첨가는 구 강내에서 임상적으로 받아들여질만한 농도임을 알 수 있었다. 


\section{결론}

이 실험의 한계 내에서 장석계 도재에 은을 첨가하는 것은 도재의 색조에 영향을 준다. 하지만 $10 \%$ 이하의 이온을 첨가한 장석계 도재는 임상적으로 받아들여질만 하다.

\section{Acknowledgements}

본 연구는 “산업통상자원부”, "한국산업기술진흥원", “호남지역사업평가원” 의 “광역경제권 선도산업 육성사 업”으로 수행된 연구결과입니다.

(This research was financially supported by the Ministry of Trade, Industry \&Energy (MOTIE), Korea Institute for Advancement of Technology (KIAT) and Honam Institute for Regional Program Evaluation through the Leading Industry Development for Economic Region)

\section{References}

1. Yun MJ. Complication and failure analysis of fixed restorations. J Dent Rehabil Appl Sci 2011;27:14959.

2. Hwang IS, Cho JY, Hwang JH, Hwang BM, Choi HM, Lee JY, Lee DG. Antimicrobial effects and mechanism(s) of silver nanoparticle. Korean J Microbiol Biotechnol 2011;39:1-8.

3. Furno F, Morley KS, Wong B, Sharp BL, Arnold PL, Howdle SM, Bayston R, Brown PD, Winship PD, Reid HJ. Silver nanoparticles and polymeric medical devices, a new approach to prevention of infection? J Antimicrob Chemother 2004;54:101924.

4. Lu Y, Liu GL, Lee LP. High-density silver nanoparticle film with temperature-controllable interparticle spacing for a tunable surface enhanced Raman scattering substrate. Nano Lett 2005;5:5-9.
5. Jain P, Pradeep T. Potential of silver nanoparticlecoated polyurethane foam as an antibacterial water filter. Biotechnol. Bioeng 2005;90:59-63.

6. Kalishwaralal K, Barathmanikanth S, Pandian SR, Deepak V, Gurunathan S. Silver nanoparticles impede the biofilm formation by Pseudomonas aeruginosa and Staphylococcus epidermidis. Colloids Surf B Biointerfaces 2010;79:340-4.

7. Wataha JC. Alloys for prosthodontic restorations. J Prosthet Dent 2002;87:351-63.

8. An JH, Choi MR, Shim HW. Shade comparative analysis of natural tooth measured by visual and two colorimeters (ShadeEye ${ }^{\circledR}$, Shadepilot ${ }^{\circledR}$ ). J Dent Rehabil Appl Sci 2013;29:81-93.

9. Paul S, Peter A, Pietrobon N, Hämmerle CH. Visual and spectrophotometric shade analysis of human teeth. J Dent Res 2002;81:578-82.

10. Kuehni RG, Marcus RT. An experiment in visual scailing of small color difference. Color Res Appl 1979;4:83-91.

11. Liau SY, Read DC, Pugh WJ, Furr JR, Russell AD. Interaction of silver nitrate with readily identifiable groups: relationship to the antibacterial action of silver ions. Lett Appl Microbiol 1997;25:279-83.

12. Feng QL, Wu J, Chen GQ, Cui FZ, Kim TN, Kim JO. A mechanistic study of the antibacterial effect of silver ions on Escherichia coli and Staphylococcus aureus. J Biomed Mater Res 2000;52:662-8.

13. Kim JY, Kim TY, Yoon JY. Antimicrobial activity and mechanism of silver. J Korean Ind Eng Chem 2009;20:251-7.

14. Esquivel JF, Chai J, Wozniak WT. Color stability of low-fusing porcelains for titanium. Int J Prosthodont 1995;8:479-85.

15. Park C, Lee GJ, Kim HJ. Effect on the externally stained IPS e.max press porcelain due to tooth brushing. J Dent Rehabil Appl Sci 2012;28:213-21.

16. Johnston WM, Kao EC. Assessment of appearance match by visual observation and clinical colorimetry. J Dent Res 1989;68:819-22. 


\section{은이온을 첨가한 장석계 도재의 분광 측색학적 평가}

\section{김지현 ${ }^{1}$, 송경우 ${ }^{2}$, 노세라 ${ }^{3}$, 윤계림 ${ }^{3}$, 윤귀덕 ${ }^{1 *}$}

${ }^{1}$ 전남대학교 치의학전문대학원 치과보철학교실, ${ }^{2}$ (주)알파덴트, ${ }^{3}$ 엔시엘코리아

목적: 이 실험의 목적은 장석계 도재에 항균성을 부여하기 위해 은을 다양한 농도로 첨가하였을 때, 은 첨가가 장석계 도재의 색조에 영향을 미치는지 알아보기 위함이다.

연구 재료 및 방법: 대조군은 은을 포함하지 않은 일반 장석계 도재를 이용하고, 은이 $5 \%, 10 \%, 20 \%, 30 \%$ 의 농도로 첨 가된 장석계 도재를 4 개의 실험군으로 하여 총 5 개의 그룹을 이용하였고, 각 그룹당 각 5 개씩 디스크 형태로 시편을 제 작하였다. 각 시편은 색차계를 이용하여 $\mathrm{L}, \mathrm{a}, \mathrm{b}$ 값을 2 번씩 측정하였다. 각 값은 SPSS를 이용하여 일원분산 통계 분석을 시행하였다.

결과: 은의 함량이 높아짐에 따라 각 그룹간 $\mathrm{L}$ 값은 거의 비슷하였고, a값은 점차 증가하고, $\mathrm{b}$ 값은 점점 감소하는 양상 을 보여주었다. 은의 함량이 높아짐에 따라 $\Delta \mathrm{E}$ 값은 유의하게 증가하였다. $5 \%$ 은 이온이 함유된 도재와 $10 \%$ 의 은 이 온이 함유된 도재는 $\Delta \mathrm{E}$ 값이 3.7 이하였다.

결론: 장석계 도재에 은을 첨가하는 것은 도재의 색조에 영향을 준다. 하지만 $10 \%$ 이하의 이온을 첨가한 장석계 도재 는 임상적으로 받아들여질만 하다.

(구강회복응용과학지 2015;31 (1):20-5)

주요어: 장석계 도재; 은 이온; 색조; 심미성

*교신저자: 윤귀덕

(500-757) 광주광역시 북구 용봉로 33 전남대학교 치의학전문대학원 보철학교실

Tel: 062-530-5638 | Fax: 062-530-5639 | E-mail: ykd@jnu. ac. kr

접수일: 2015년 2월 6일 | 수정일: 2015년 3월 6일 | 채택일: 2015년 3월 2일 